\title{
Electrochemical Studies of Selected Lanthanide and Californium Cryptates
}

Matthew L. Marsh, ${ }^{\dagger}$ Frankie D. White,${ }^{\dagger}$, David S. Meeker, ${ }^{\dagger}$ Carla D. McKinley, ${ }^{\dagger}$ David Dan, ${ }^{\dagger}$ Cayla Van Alstine,${ }^{\dagger}$ Todd N. Poe, ${ }^{\dagger}$ Danielle L. Gray ${ }^{\delta}$, David E. Hobart,${ }^{\dagger}$ and Thomas E. Albrecht-Schmitt ${ }^{\dagger} * *$

tDepartment of Chemistry \& Biochemistry, Florida State University, 95 Chieftain Way, RM. 118 DLC, Tallahassee, FL, 32306, USA.

¿Department of Chemistry, University of Illinois at Urbana-Champaign, Champaign, Illinois 61820 USA

*albrecht-schmitt@chem.fsu.edu and dhobart15@gmail.com 
Table of Contents:

\section{Page}

$\begin{array}{ll}\text { Synthesis } & \text { S03-S06 }\end{array}$

$\begin{array}{ll}\text { Electrochemistry } & \text { S06-S20 }\end{array}$

$\begin{array}{ll}\text { Absorption and Emission Spectroscopy } & \text { S21-S23 }\end{array}$ 


\section{Synthesis}

[Sm(2.2.2-cryptand)](otf) $)_{3}: 30.03 \mathrm{mg}$ of $\mathrm{Sm}(\mathrm{otf})_{3}, 13.0 \mathrm{mg}$ of 2.2.2-cryptand, and $2.3 \mathrm{~mL}$ of a 9:1 mixture of $\mathrm{CH}_{3} \mathrm{CN} / \mathrm{DMF}$ were mixed together for initial experiments. For a more optimal solution study, the solvent was switched to THF. $32.3 \mathrm{mg}$ of anhydrous Sm(otf) was mixed with $18.0 \mathrm{mg}$ of 2.2.2-cryptand in $2.3 \mathrm{~mL}$ of anhydrous THF in an argon atmosphere $(0.021 \mathrm{M}) . \mathrm{Sm}(\mathrm{otf})_{3}$ is not very soluble in THF but becomes very soluble after the addition of cryptand. An individual CV as well as a scan-rate dependent CV is provided for the cryptate in Figures S14-S15.

[Yb(2.2.2-cryptand)](otf) $)_{3}: 15.5 \mathrm{mg}$ of $\mathrm{Yb}(\mathrm{otf})_{3}, 12.9 \mathrm{mg}$ of 2.2.2-cryptand, and $1.2 \mathrm{~mL}$ of THF were mixed together $(0.021 \mathrm{M})$. $\mathrm{Yb}(\mathrm{otf})_{3}$, was very soluble in THF. An individual CV as well as a CV comparing the triflate and cryptate shift is shown in Figures S16-S17.

[Eu(2.2.2-cryptand)](otf) $)_{3}: 15.0 \mathrm{mg}$ of Eu(otf) $3,11.5 \mathrm{mg}$ of 2.2.2-cryptand, and $1.2 \mathrm{~mL}$ of THF were mixed together $(0.021 \mathrm{M})$. Eu(otf $)_{3}$, unlike $\mathrm{Sm}$ and $\mathrm{Yb}$, produces a pale-yellow color in THF. A CV comparing the triflate and cryptate shift is shown in Figure S18.

$\mathrm{Cf}(\mathrm{otf})_{3}: 1.0 \mathrm{mg} \mathrm{CfCl}{ }_{3} \times \mathrm{H}_{2} \mathrm{O}$ was converted to $\mathrm{Cfl}_{3} \cdot \mathrm{H}_{2} \mathrm{O}$ and dissolved in $0.5 \mathrm{~mL}$ THF. Then $3.2 \mathrm{mg}$ Agotf (otf $=$ triflate) was dissolved in $0.5 \mathrm{~mL}$ THF and mixed together to precipitate Agl. It is important to note that the solution sat for 24 hours before filtration to collect as much Agl out as possible. Therefore, some initial radiolysis of the solution had taken place before experiments were conducted. Later, addition of $8.0 \mathrm{mg}$ of cryptand was added to the solution of THF to form the cryptate. 
Mixtures of [Ln(2.2.2-cryptand)](otf) $)_{3}$ For this experiment, we scaled down the quantities of material to reflect the usage of an actinide such as Cf. $3 \mathrm{mg}$ of $\mathrm{Sm}(\mathrm{otf})_{3}, 3 \mathrm{mg}$ of Eu(otf) $)_{3}$, and $4 \mathrm{mg}$ of $\mathrm{Yb}(\mathrm{otf})_{3}$ were mixed together with $8 \mathrm{mg}$ of 2.2.2-cryptand in $1.2 \mathrm{~mL}$ of THF. A CV comparing the triflate and cryptate shift for the mixture of lanthanides is shown in Figure S19.

[Ln(2.2.2-cryptand)(THF)][BPh $]_{2}$ Solution Preparation. $19.5(0.05 \mathrm{mmol}) \mathrm{mg}$ of $\mathrm{Sml}_{2}$ was dissolved in $4 \mathrm{~mL}$ of THF. $56.2(0.1 \mathrm{mmol}) \mathrm{mg}$ of tetrabutylammonium tetraphenylborate was added and the solution stirred for three hours. A solution of 2.2.2-cryptand (21.4 mg, $0.06 \mathrm{mmol}$ ) in $1 \mathrm{~mL}$ of THF was then added, and a green precipitation formed. The solution was then centrifuged and the supernatant removed. The green precipitant was dissolved in $2 \mathrm{~mL}$ of anhydrous acetonitrile resulting in a red solution used for the electrochemical experiments. The Eu and Yb solutions were prepared in the same fashion with the following amounts: $10.6 \mathrm{mg} \mathrm{Eul} 2$ was dissolved in $2 \mathrm{~mL}$ THF, $23.1 \mathrm{mg}$ tetrabutylammonium tetraphenylborate was added, and the solution was stirred for 3 hours (pale yellow). $10.3 \mathrm{mg}$ 2.2.2-cryptand was dissolved in $1 \mathrm{~mL}$ THF, the solution became colorless, and precipitated. The precipitate was later dissolved in $3 \mathrm{~mL}$ of $\mathrm{CH}_{3} \mathrm{CN}$ (colorless). A similar procedure was followed for $\mathrm{Yb}$, using $9.9 \mathrm{mg} \mathrm{Ybl}_{2}, 23.1 \mathrm{mg}$ tetrabutylammonium tetraphenylborate, and $10.3 \mathrm{mg}$ 2.2.2-cryptand. The only difference was that nothing precipitated out of solution upon cryptand addition, and electrochemistry experiments were thus conducted on $\mathrm{THF} / \mathrm{CH}_{3} \mathrm{CN}$ mixtures. (Figure S20). 


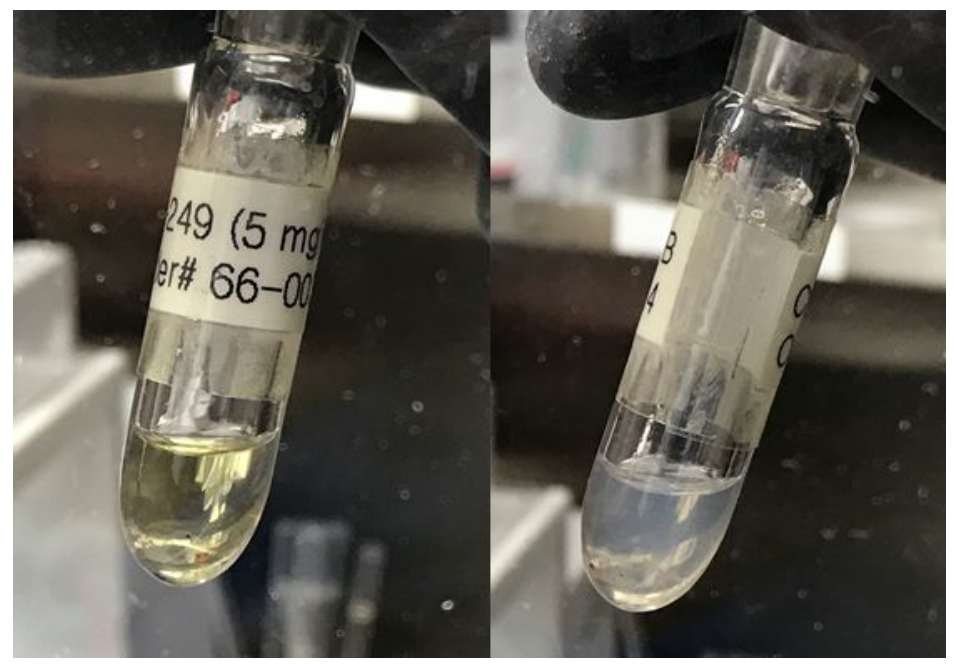

Figure $\mathrm{S1} \mathrm{Cfl}_{3}$ (left) and $\mathrm{Cf}(\mathrm{otf})_{3}$ (right) in THF. The suspension seen in this picture comes from unsettled Agl that is leftover from its in situ metathesis preparation.

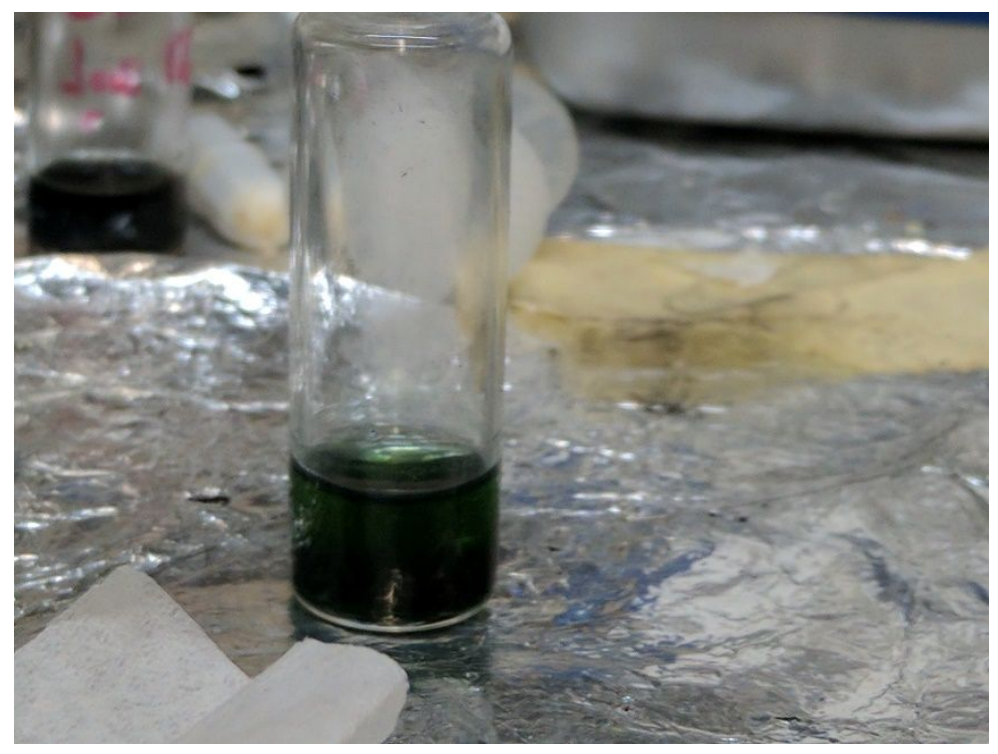

Figure S2. [Sm(2.2.2-cryptand)(THF)][BPh $]_{2}$ precipitated in a solution of THF. 


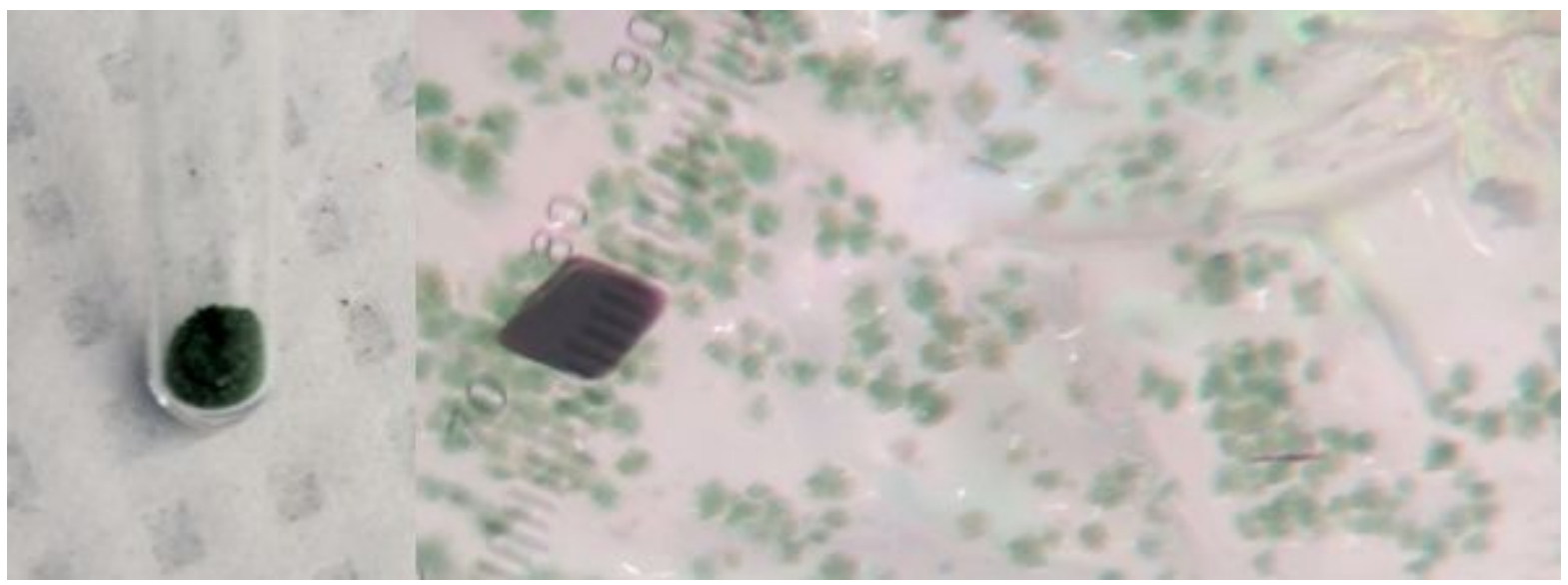

Figure S3. [Sm(2.2.2-cryptand)(THF)][BPh $]_{2}$ in powder form (left) and crystals (green, right). Note: the violet crystal is a secondary product.

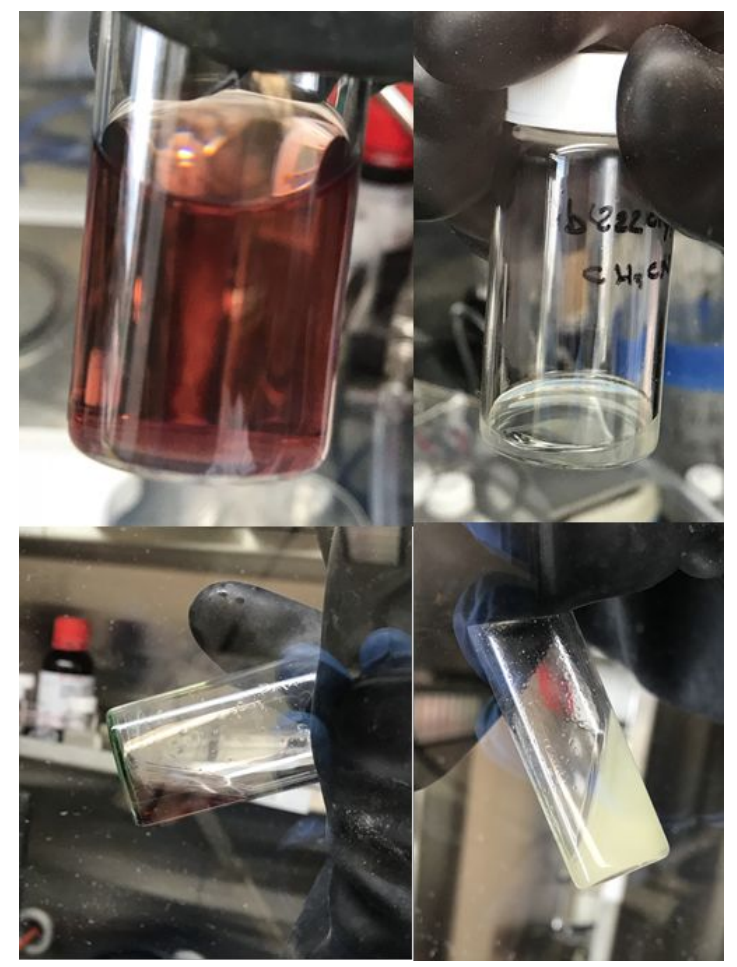

Figure S4. Pictures of $\left[\mathrm{Sm}(2.2 .2-\text { cryptand)(THF)][BPh }]_{2}\right.$ completely dissolved (top left) and partially dissolved (bottom left) in $\mathrm{CH}_{3} \mathrm{CN}, \mathrm{Yb}$ (top right) in $\mathrm{CH}_{3} \mathrm{CN} / \mathrm{THF}$, and [Eu(2.2.2-cryptand)(THF)][BPh$]_{2}$ (bottom right) in $\mathrm{CH}_{3} \mathrm{CN}$. 


\section{Electrochemistry}

For $\mathrm{Cf}$, the greatest uncertainty in the entire experiment was with respect to its concentration. Variables that affected this were incomplete transference of $\mathrm{Cfl}_{3}$ into the $\mathrm{Cf}\left(\mathrm{otf}_{3}\right)$ solution, variable evaporation rates of $\mathrm{THF}$ depending upon glovebox temperature, pressure, electrode configuration, and internal solution heating from radioactive decay, and the suspected chemical transformations throughout the experiments involving EC mechanisms and radiolysis. Nevertheless, some statistical measures remained relatively good throughout the entire set of experiments. Time stamps, for example, indicate the first CV was recorded at 10:32 a.m. and the last CV was recorded at 5:11 p.m. The morning experiments sought to locate the irreversible triflate peaks of $\mathrm{Cf}$, anticipating that they could very well be outside the bounds of the reductive potential window. Precluding this finding was a strong peak, and after some characterization, was determined to most likely be residual I- that was still in solution. Surveying the potential window farther out, several more redox-active constituents began to appear. For example, one potential radiolysis product of THF is 2hydroxyperoxytetrahydrofuran, a peroxide that most likely is redox-sensitive and will attack other chemical constituents at reductive potentials. Eventually, the Cf triflate peak was found near the boundary of the electrochemical window at $E_{\text {cathode }}=-2.50 \mathrm{~V}$ vs. $\mathrm{Fc} / \mathrm{Fc}^{+}$(Figure S21). After an intermission, the afternoon experiments were conducted on the complexed cryptate. With the solution mostly dried out, a new addition of fresh solvent was administered. An example of a scan-rate dependence plot for Cf cryptate is given for 
the scans conducted in the anodic direction (Figure S22). Additionally, differential pulse voltammograms (DPV's) conducted in the cathodic and anodic directions are shown in Figure S23. Only at this later stage of experiments were tangible deviations against a known quasi-reversible potential able to be plotted. From this fact, the chronological order of experiments could not assume a negligible change for some of the factors stated above over the course of 4 hours and 41 minutes.

Additionally, to help the reader we will describe the some of the statistical plots of Figures S6-S9 here. For a reversible process, $E_{\text {cathode }}$ and $E_{\text {anode }}$ should remain independent of the scan rate. For a quasi-reversible process, one or both of these peaks can shift due to scan rate changes. Additionally, varying the switching potential where the scan changes from cathodic to anodic is known to affect the rate constant calculation, thereby also impacting the observed CV under quasi-reversible conditions. The concentration and direction of scanning can also affect this value as well. In this sense, we wanted to be thorough with respect to observations of $E_{c a t h o d e}, E_{a n o d e}, I_{p c}, I_{p a}$, and not to attribute unexpected shifts and/or current changes due to a specific methodology instead of radiolytic degradation. This also particularly helps when trying to make comparisons between $\mathrm{Cf}$ and the lanthanides.

For example, in Figure $\mathrm{S} 6$ there is a cathodic deviation of $\mathrm{E}_{\text {cathode }}$ with increasing scan rate. This can be expected for a quasi-reversible process. However, the boxes demonstrate that while the overall quasi-reversible trend can be identified, the 
methodology also impacts the potentials observed. A mirror example for $E_{\text {anode }}$ is shown in Figure S7.

Figure S8 is a good example of how a trend was able to be found despite inconsistent current data from some of the experiments. For Cf, some of the later experiments had worse data due to radiolytic decay on the solvent. Generally, this impacted identifying $I_{p c}$ and $I_{p a}$ values the most due to other redox-active constituents of the solvent. Nevertheless, the statistical plot shows the same trend as the trend from Figure 2, validating that methodology was unlikely causing the current aberrations observed. This could then be attributed to radiolytic decay.

Figure S9 also confirms in a separate way what Figure S8 identifies. In this plot, each individual method has its $E_{\text {cathode }}$ currents plotted against the square root of scan rate. For a reversible or quasi-reversible electrochemical step, linear or near linear observations should follow. What we discover was that linearity is greatly affected by the methodology used. However, instead of mistakenly attributing this consequence to the experiment, it was noted that linearity becomes worse with respect to the chronological order of the method used. Therefore, this can much more likely be attributed to radiolysis.

Considering that there is not any similar electrochemistry published for Cf already, this documentation of how much the radiolytic decay affected the use of the technique could be very valuable for future investigations. 


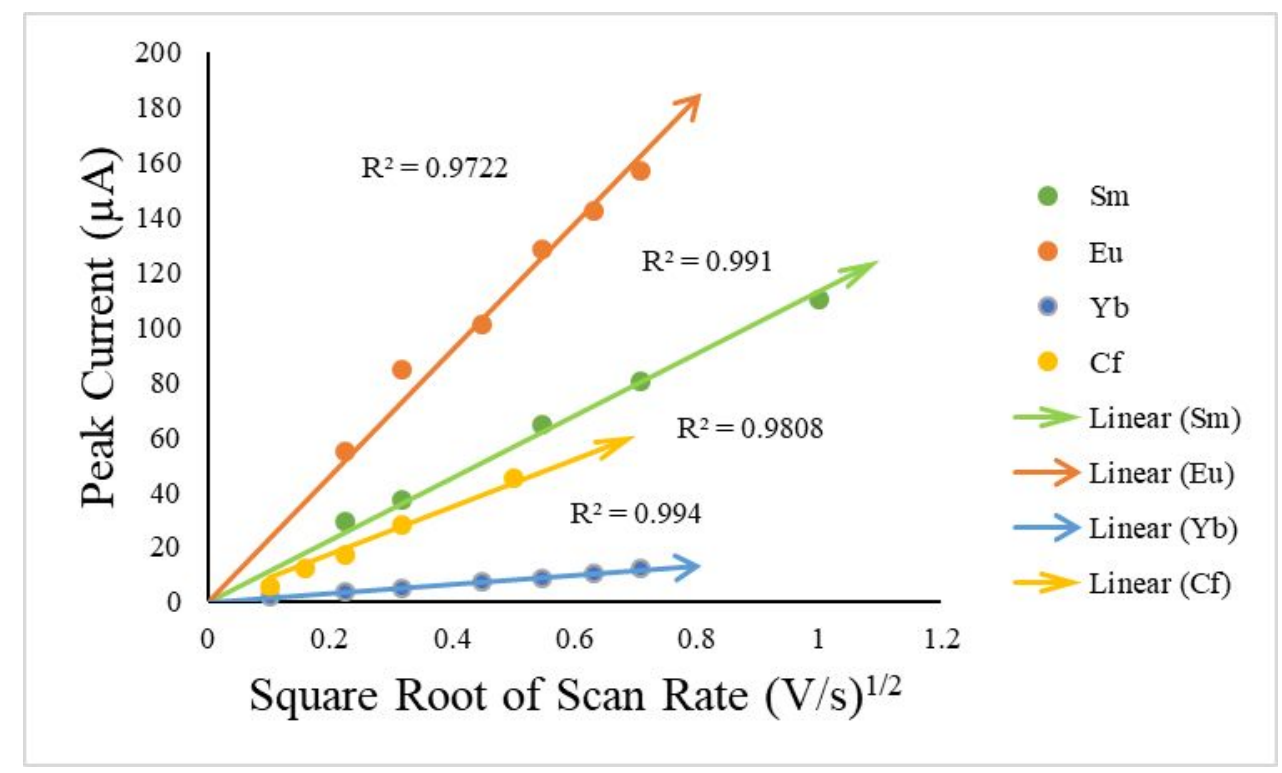

Figure S5. Plot of the scan rate $\left(v^{1 / 2}\right)$ vs. the cathodic peak current $\left(I_{p c}\right)$ showing linear dependence for cryptates of Eu (orange), Yb (blue), Sm (green), and Cf (yellow).

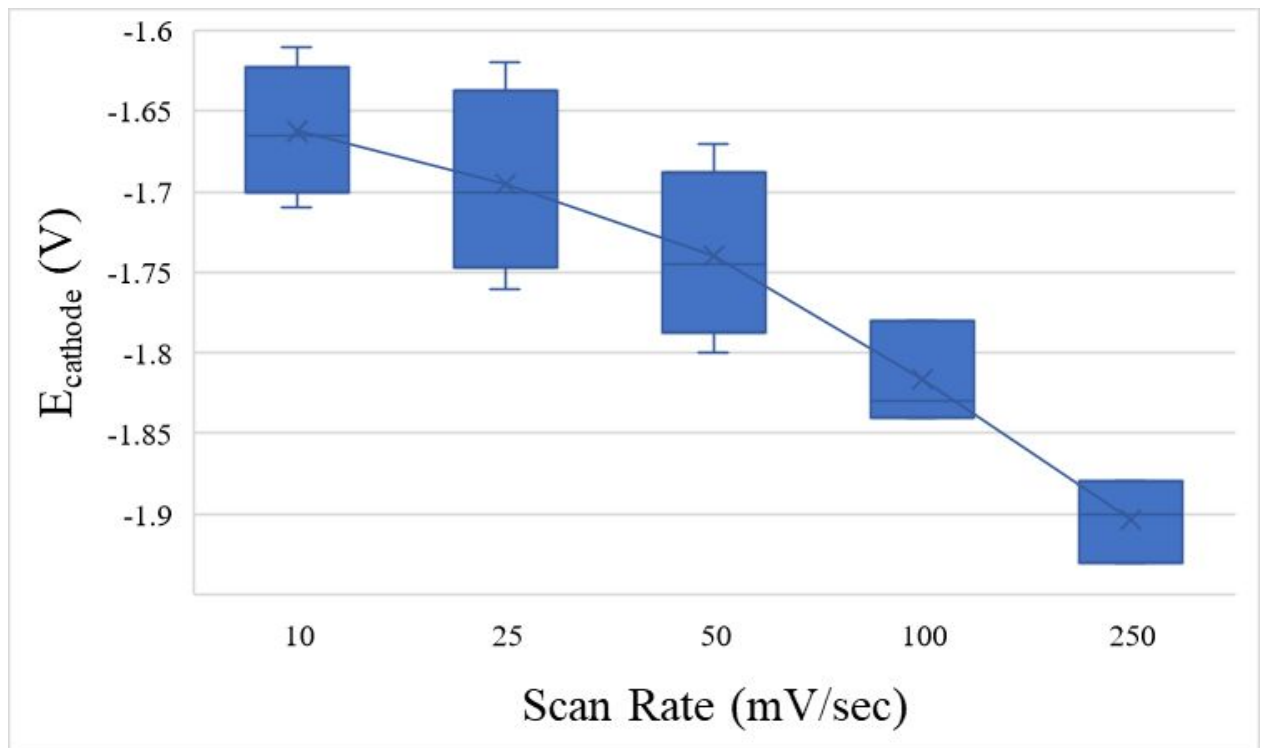

Figure S6. Plot of the statistical variance of cathodic wave potential versus scan rate for the larger window/cathodic scan/concentrated dataset, Shorter window/cathodic 
scan/concentrated dataset, Shorter window/anodic scan/concentrated dataset, and Shorter window/cathodic scan/dilute dataset.

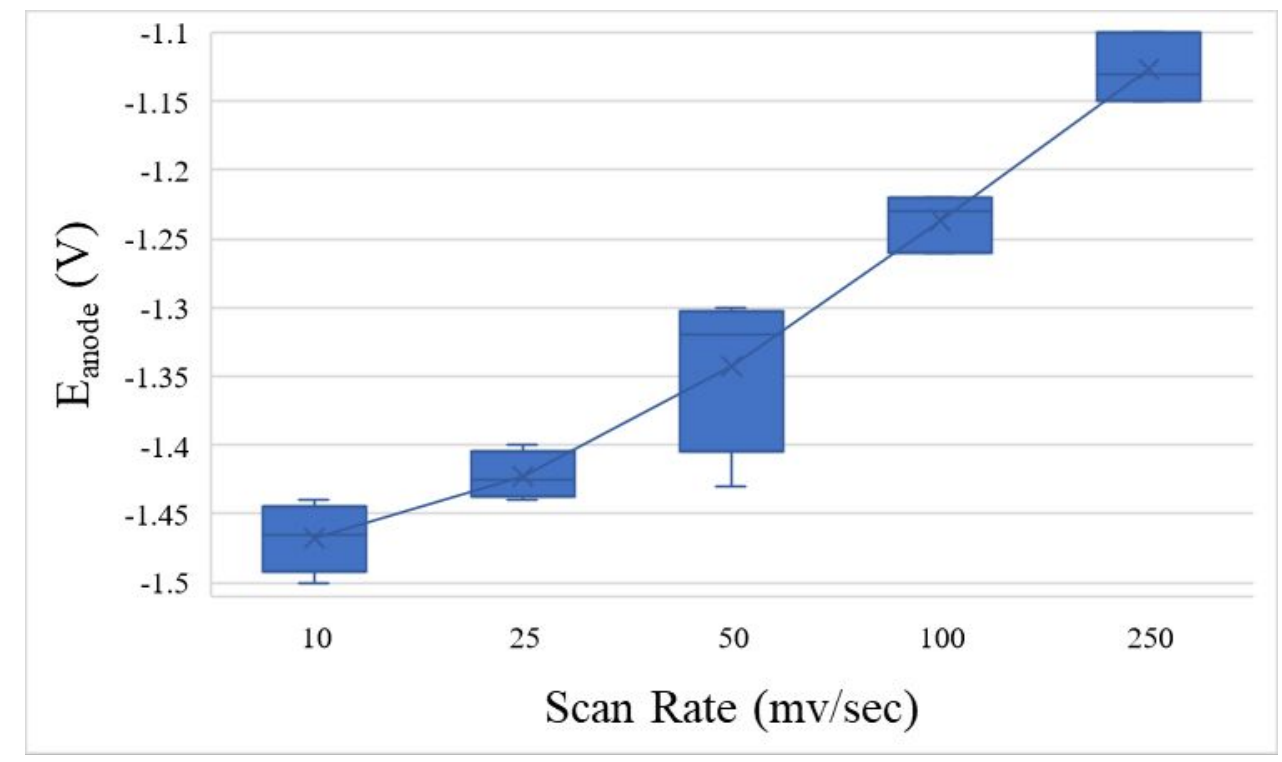

Figure S7. Plot of the statistical variance of anodic wave potential versus scan rate for the larger window/cathodic scan/concentrated dataset, Shorter window/cathodic scan/concentrated dataset, Shorter window/anodic scan/concentrated dataset, and Shorter window/cathodic scan/dilute dataset. 


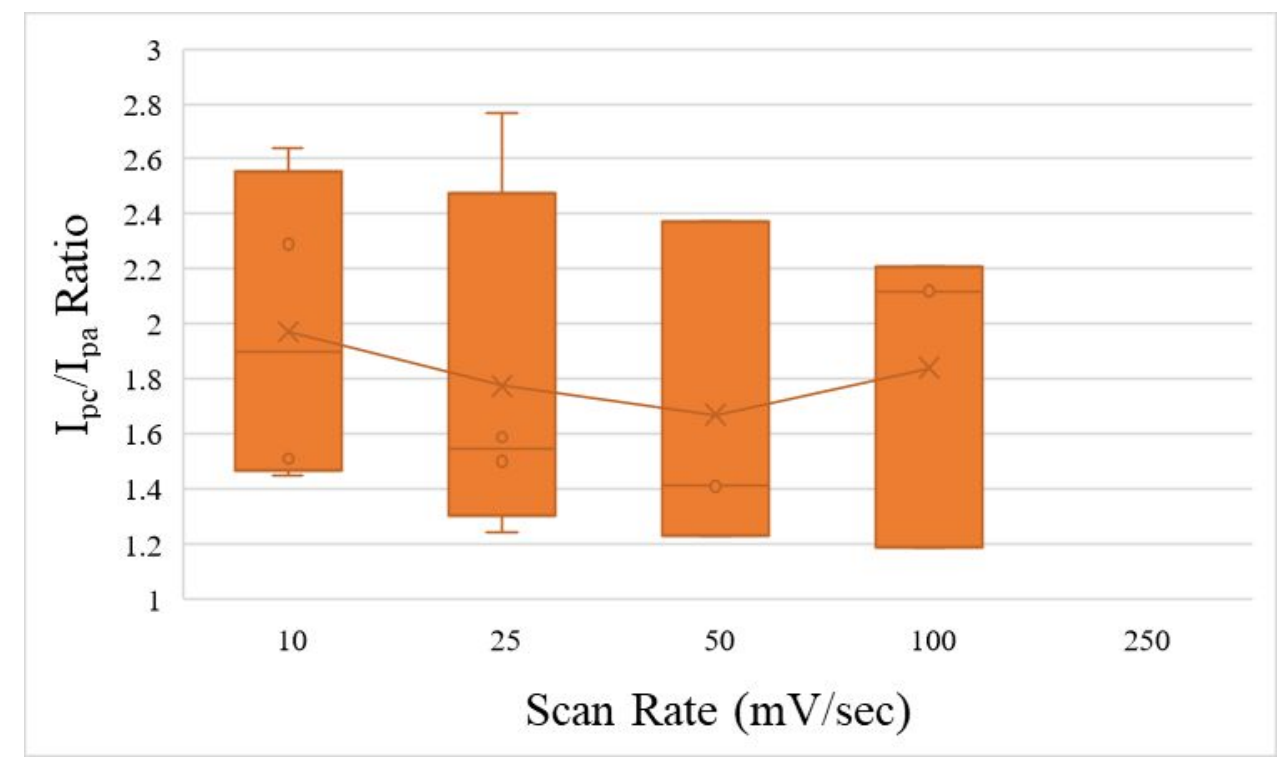

Figure S8. Plot of the statistical variance of $I_{p c} / I_{p a}$ ratio versus scan rate for the larger window/cathodic scan/concentrated dataset, Shorter window/cathodic scan/concentrated dataset, Shorter window/anodic scan/concentrated dataset, and Shorter window/cathodic scan/dilute dataset.

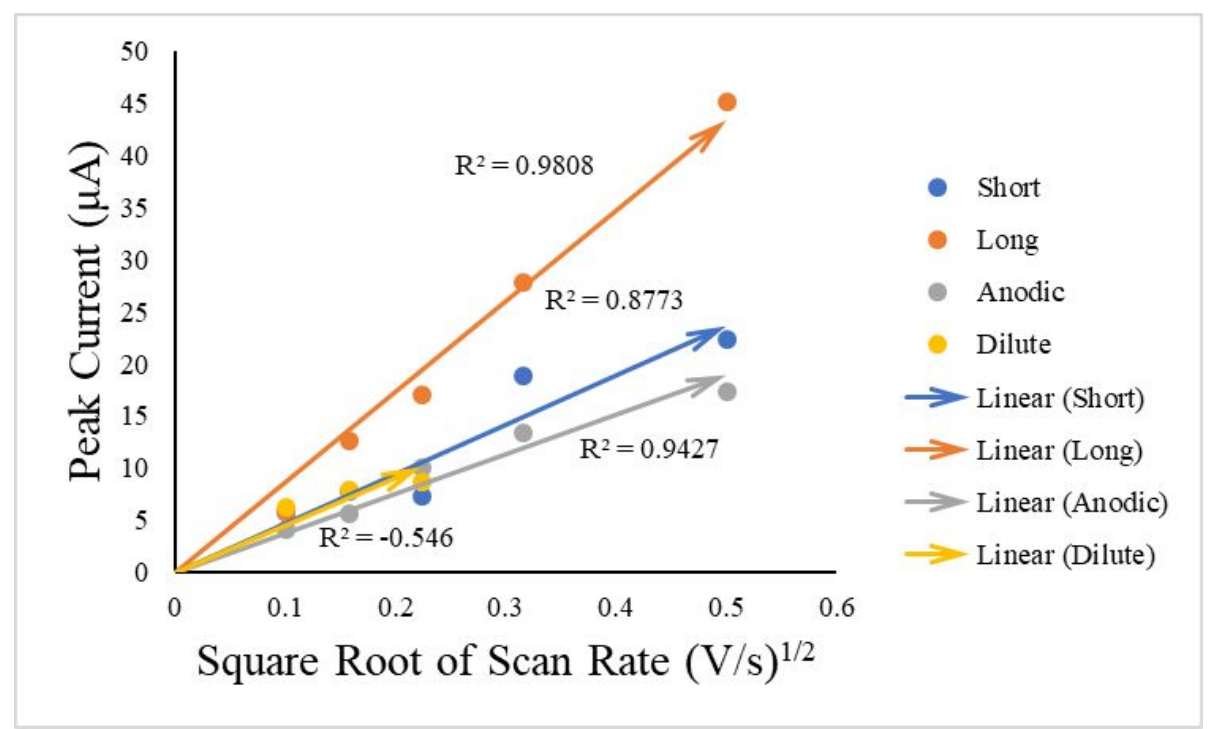


Figure S9. Plot of the scan rate $\left(v^{1 / 2}\right)$ vs. the cathodic peak current $\left(I_{p c}\right)$ showing relative linear fits of $\mathrm{Cf}$ cryptates depending on the chronological collection method marked as follows: Larger window/cathodic scan/concentrated (orange), Shorter window/cathodic scan/concentrated (blue), Shorter window/anodic scan/concentrated (gray), and Shorter window/cathodic scan/dilute (yellow).

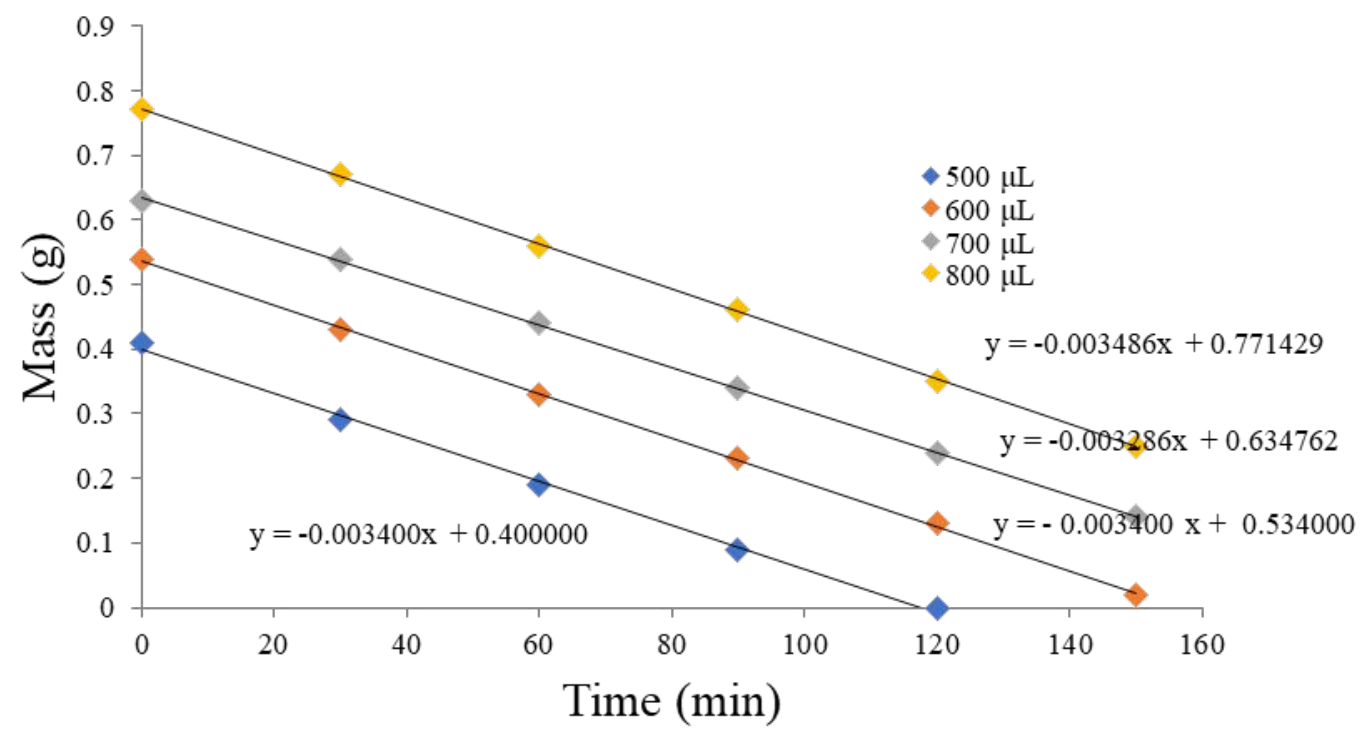

Figure S10. Calibrations of various starting amounts of THF yield a consistent evaporation rate of $3.82 \mu \mathrm{L} / \mathrm{min}$ approximating the experimental conditions used. 


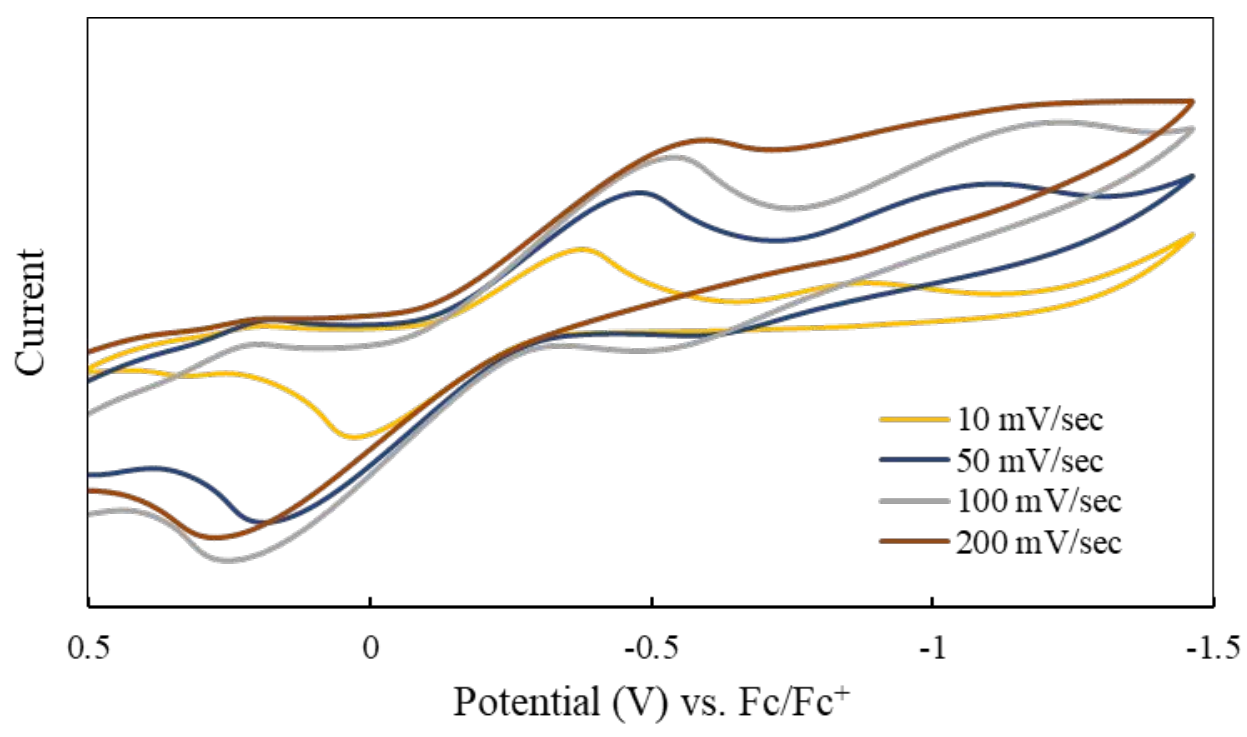

Figure S11. CV for 1:1:1 molar equivalents for cryptates of $\mathrm{Eu}, \mathrm{Yb}$, and $\mathrm{Sm}$ at various scan rates.

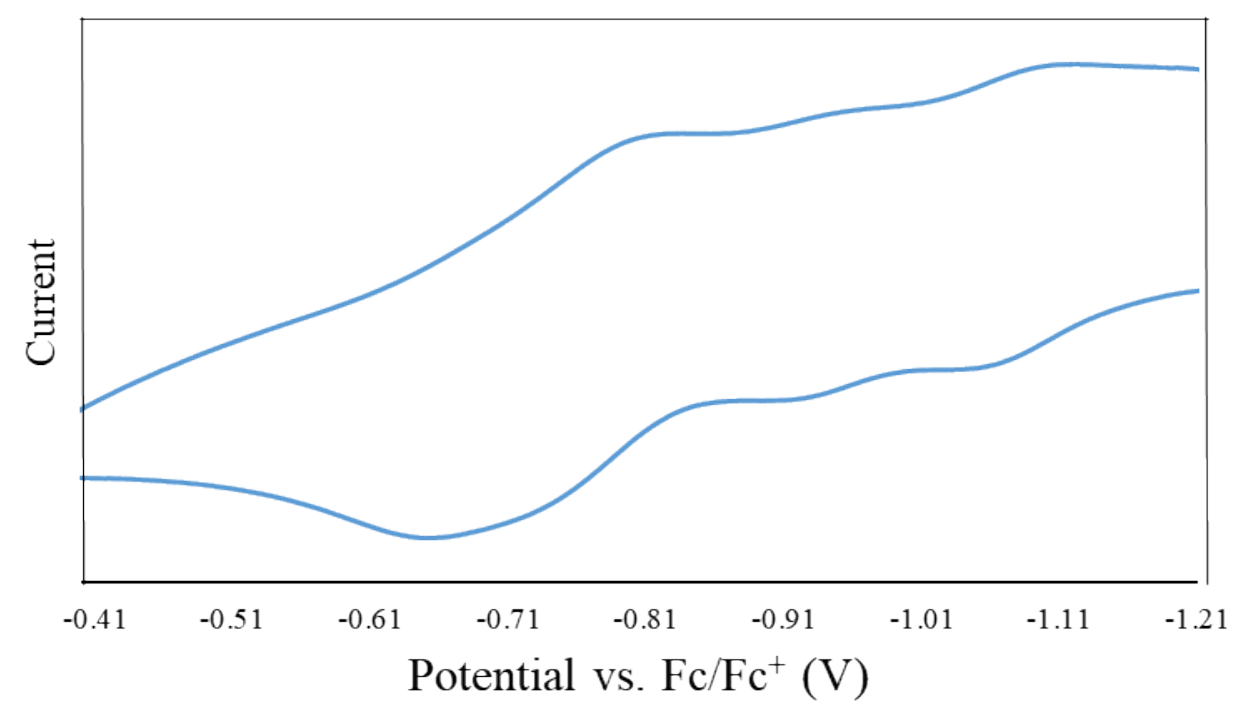

Figure $\mathrm{S} 12 . \mathrm{CV}$ of $\mathrm{Yb}\left(\mathrm{BPh}_{4}\right)_{2}$ in a $\mathrm{CH}_{3} \mathrm{CN} / \mathrm{THF}$ mixture showing the redox couples in order of least to most cathodic peaks for $\mathrm{I}^{-}, \mathrm{BPh}_{4}^{-}$, and $\mathrm{Yb}(\mathrm{III}) / \mathrm{Yb}$ (II) $\left(0.1 \mathrm{M} \mathrm{NPr}_{4} \mathrm{BArF}_{4}, \mathrm{~T}=25^{\circ} \mathrm{C}\right.$, and $\mathrm{v}=100 \mathrm{mV} / \mathrm{sec}$ ). 


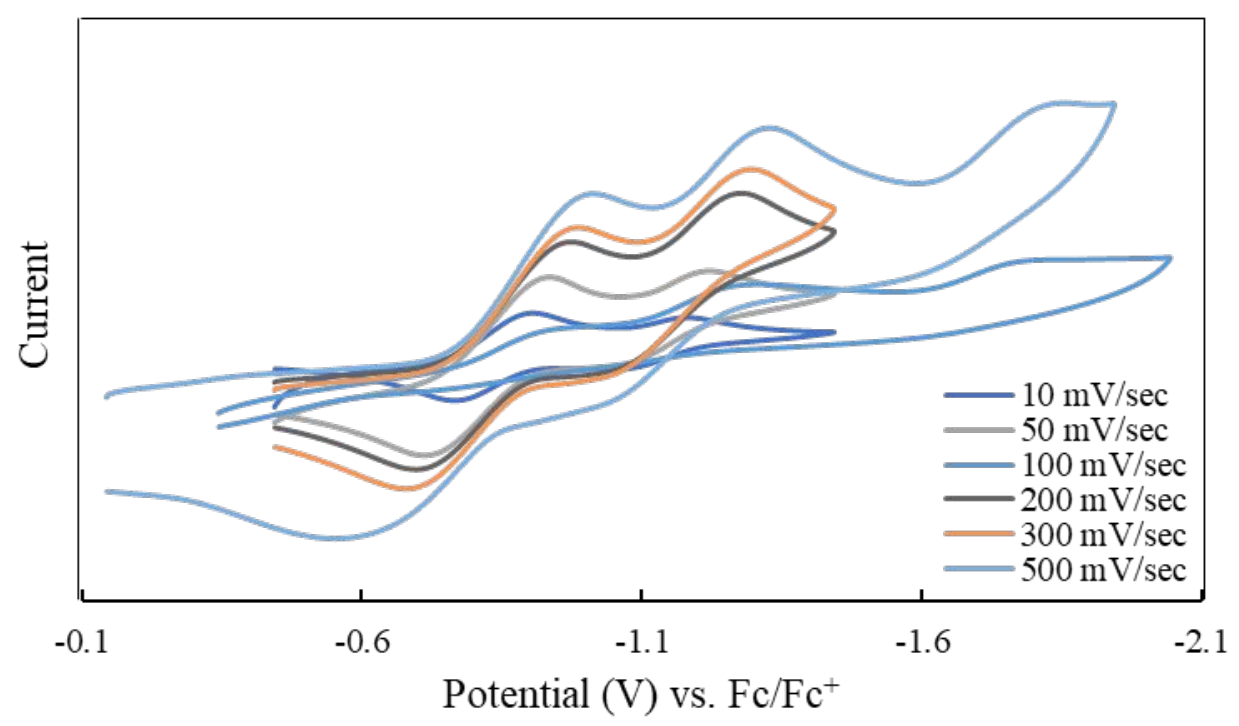

Figure $\mathrm{S}$ 13. $\mathrm{CV}$ of $[\mathrm{Sm}(2.2 .2-\mathrm{cryptand})(\mathrm{THF})]\left[\mathrm{BPh}_{4}\right]_{2}$ at various scan rates.

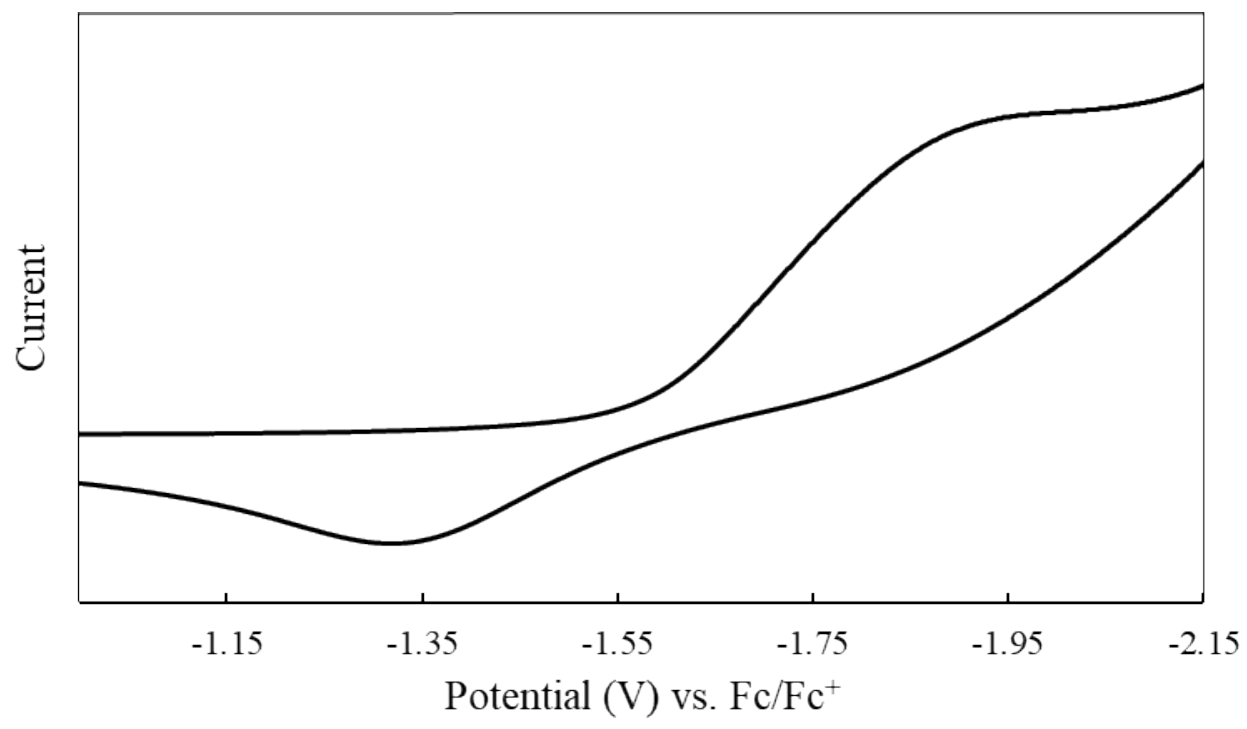

Figure S14. CV for the quasi-reversible couple of Sm cryptate $\left(T=25^{\circ} \mathrm{C}\right.$ and $v=50$ $\mathrm{mV} / \mathrm{sec})$. 


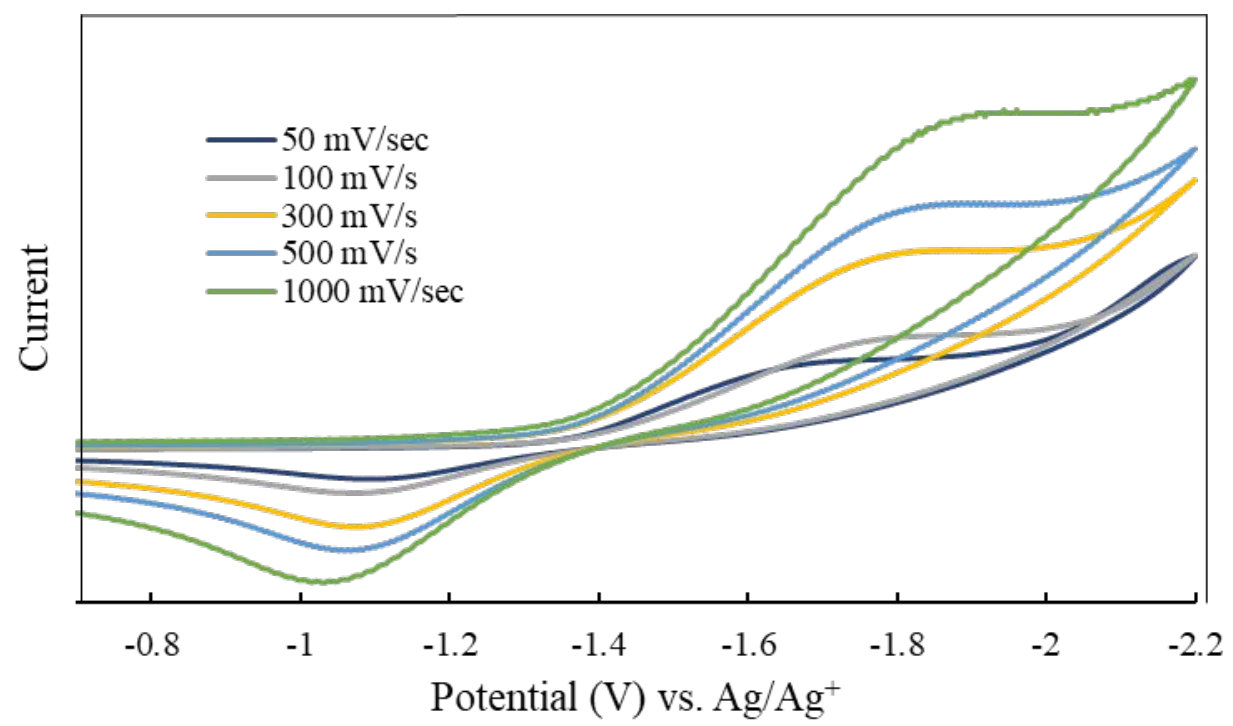

Figure S15. CV showing various scan rates for Sm cryptate.

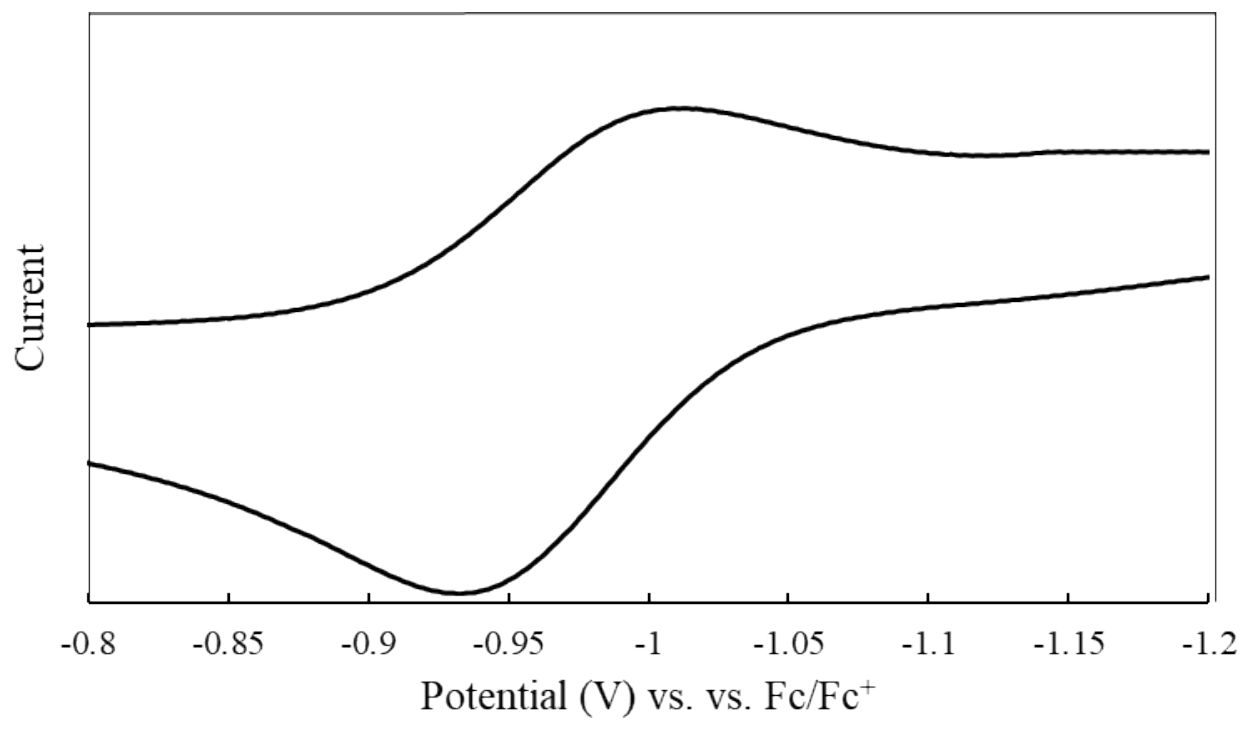

Figure S16. CV showing the reversible couple of $\mathrm{Yb}$ cryptate $\left(T=25^{\circ} \mathrm{C}\right.$ and $\mathrm{v}=50$ $\mathrm{mV} / \mathrm{sec})$. 


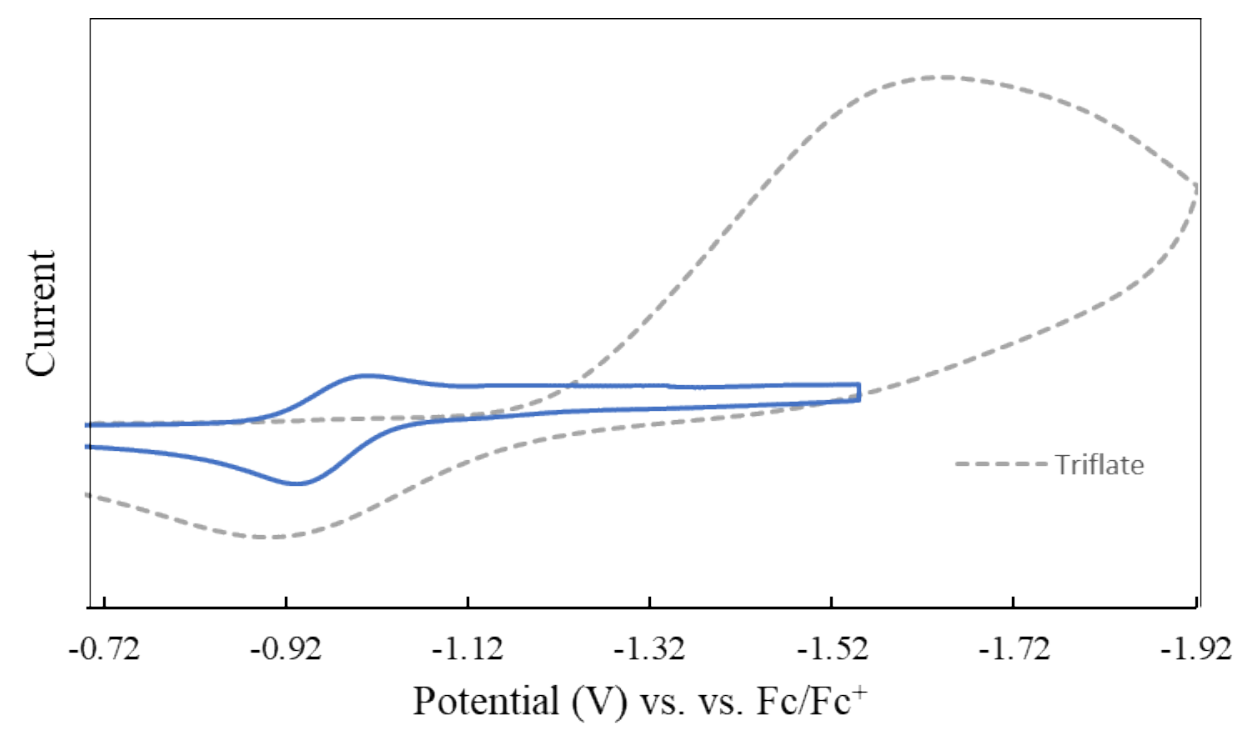

Figure S17. $\mathrm{CV}$ for the $\mathrm{Yb}$ triflate (green) and the $\mathrm{Yb}$ cryptate (blue) $\left(\mathrm{T}=25^{\circ} \mathrm{C}\right.$ and $\mathrm{v}=50$ $\mathrm{mV} / \mathrm{sec})$.

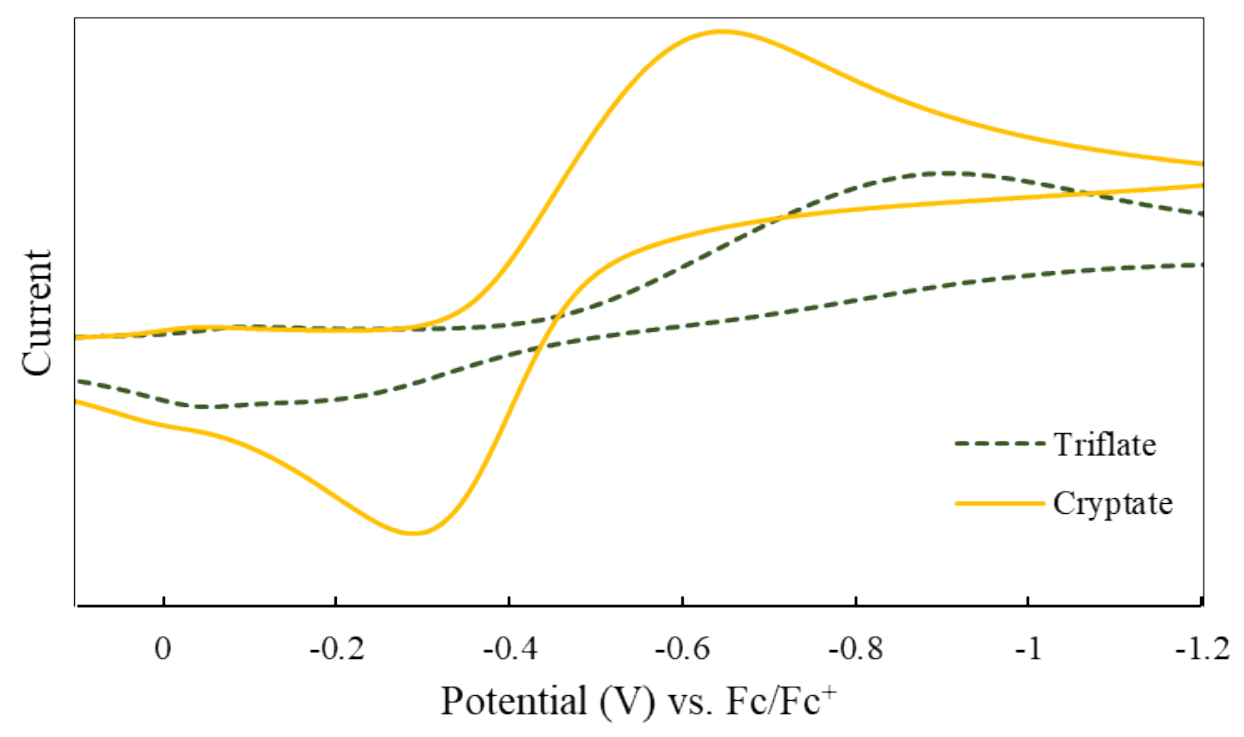

Figure S18. CV for the Eu triflate (blue) and the Eu cryptate (orange) $\left(\mathrm{T}=25^{\circ} \mathrm{C}\right.$ and $\mathrm{v}=$ $50 \mathrm{mV} / \mathrm{sec})$. 


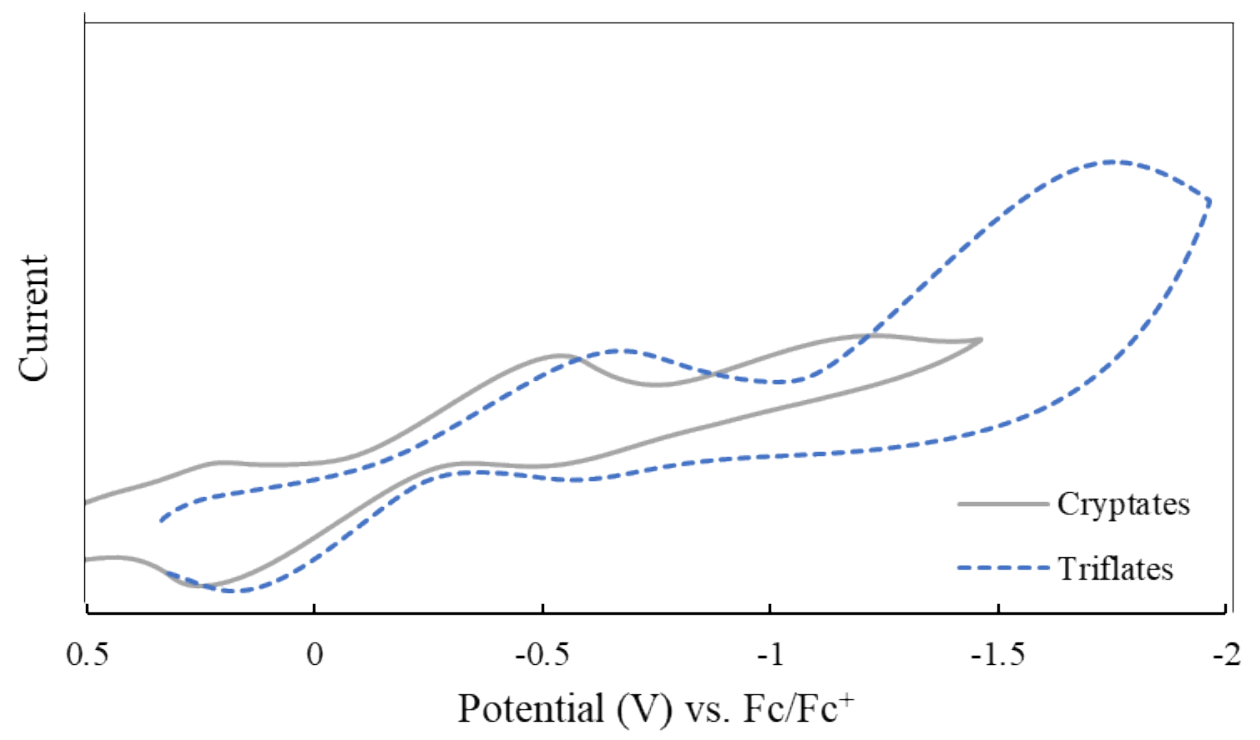

Figure S19. CV with 1:1:1 molar equivalents for the triflates (blue) and cryptates (gray) of $\mathrm{Eu}, \mathrm{Yb}$, and $\mathrm{Sm}$ mixed together simultaneously $\left(\mathrm{T}=25^{\circ} \mathrm{C}\right.$ and $\left.\mathrm{v}=100 \mathrm{mV} / \mathrm{sec}\right)$.

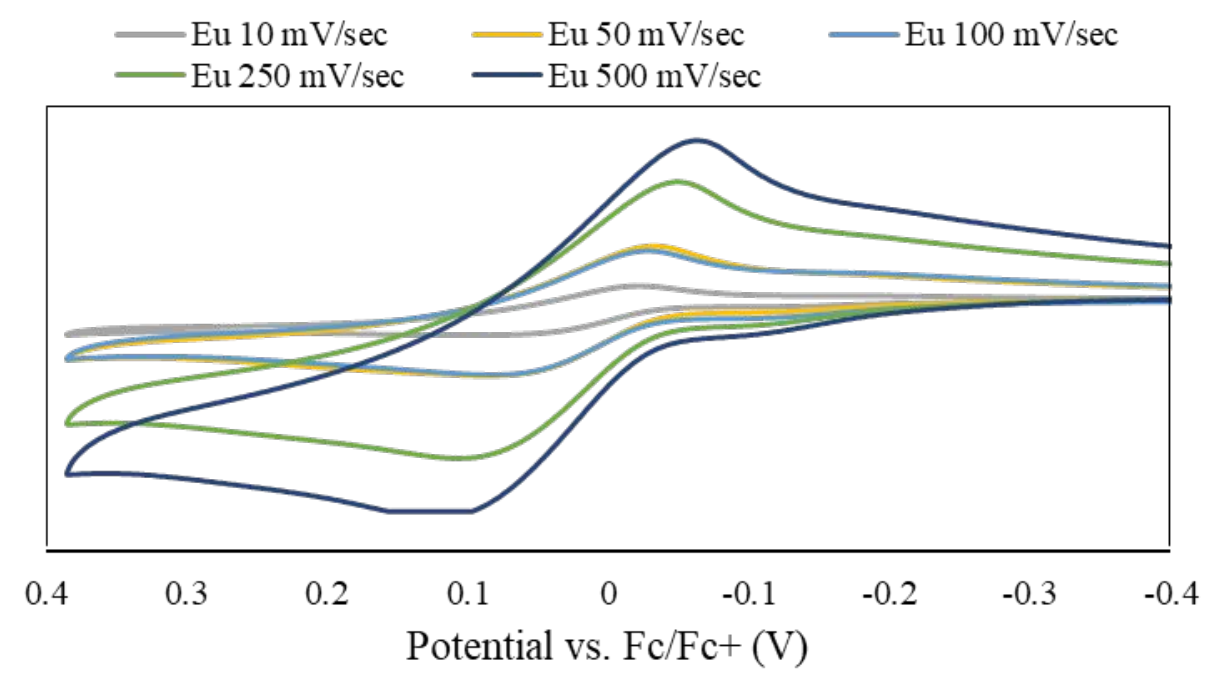

Figure S20. CV of [Eu(2.2.2-cryptand)(THF)][BPh $]_{2}$ at various scan rates. 


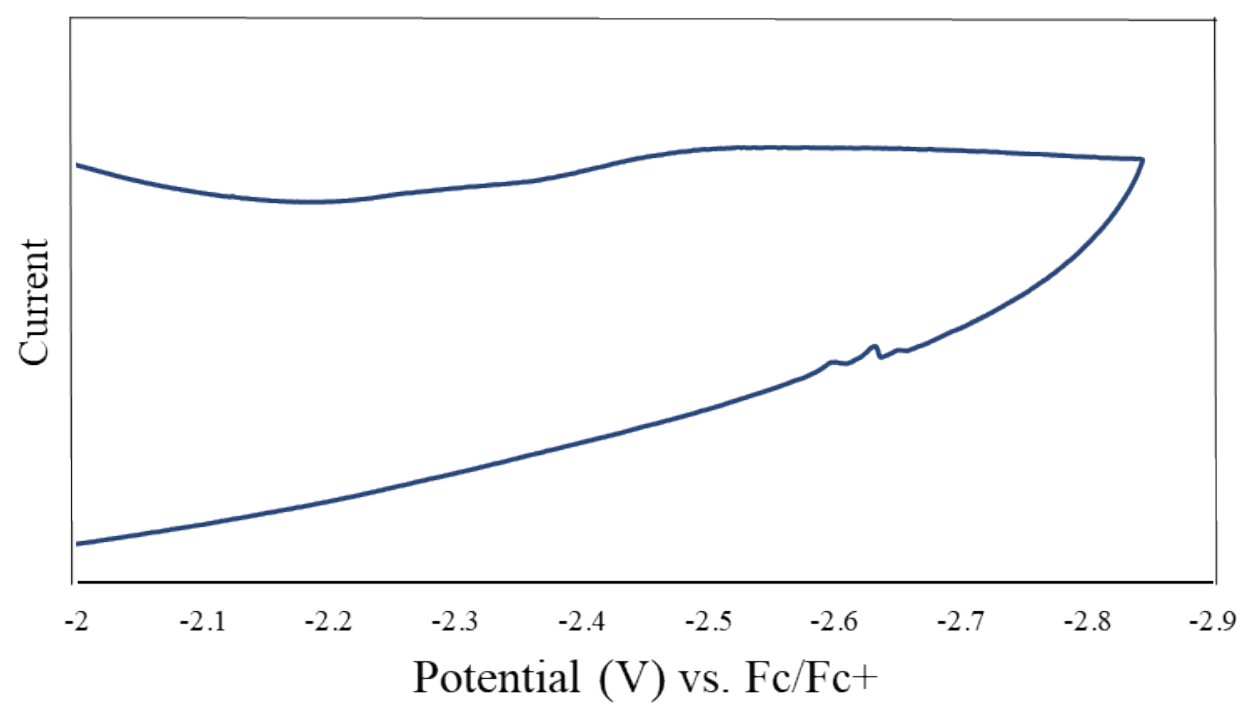

Figure S21. CV showing the broad, irreversible $E_{\text {cathode }}$ peak of uncomplexed $\mathrm{Cf}(\mathrm{otf})_{3}(0.1$ $\mathrm{M} \mathrm{NPr}_{4} \mathrm{BAr}_{4}, \mathrm{~T}=28^{\circ} \mathrm{C}$, and $\left.\mathrm{v}=100 \mathrm{mV} / \mathrm{sec}\right)$

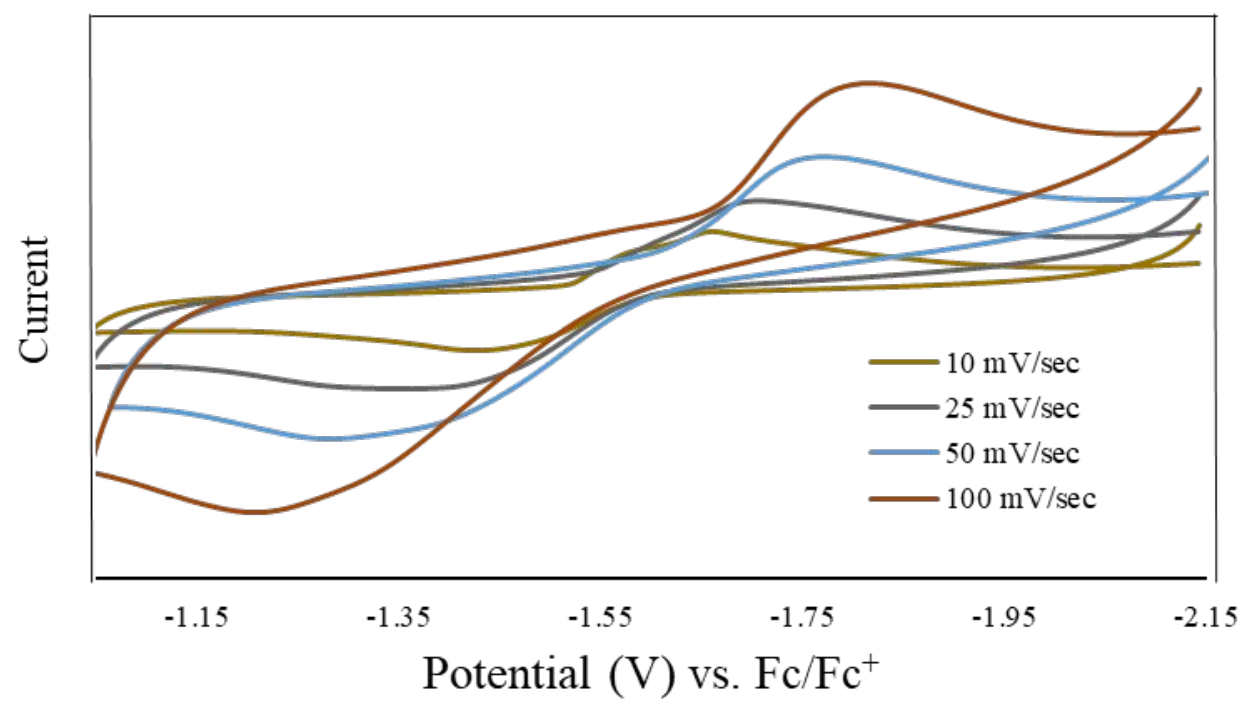

Figure S22. CV of $[\mathrm{Cf}(2.2 .2$-cryptand $)](\text { otf })_{3}$ for various scan rates conducted in the anodic direction. (0.1 M NPr $\mathrm{BAr}_{4}{ }_{4}$ and $\left.\mathrm{T}=28^{\circ} \mathrm{C}\right)$. 


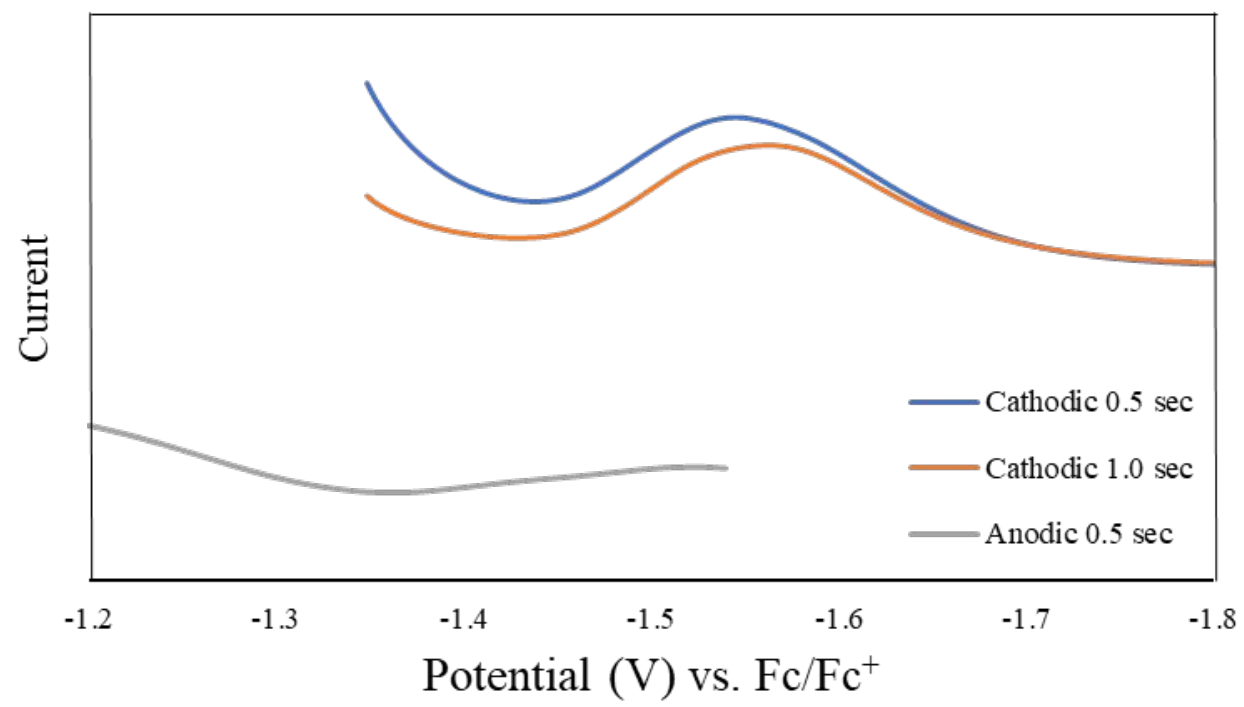

Figure S23. Differential pulse voltammogram (DPV) of [Cf(2.2.2-cryptand)](otf) $)_{3}$ for various pulse times $(0.5 \mathrm{sec}$ and $1.0 \mathrm{sec})$ conducted both in the cathodic and anodic direction. $\left(0.1 \mathrm{M} \mathrm{NPr}_{4} \mathrm{BArF}_{4}\right.$ and $\left.\mathrm{T}=28^{\circ} \mathrm{C}\right)$. The cathodic direction yields an $\mathrm{E}_{\text {cathode }}=-$ $1.54 \mathrm{~V}$ while the anodic direction yields $\mathrm{E}_{\text {anode }}=-1.35 \mathrm{~V}$.

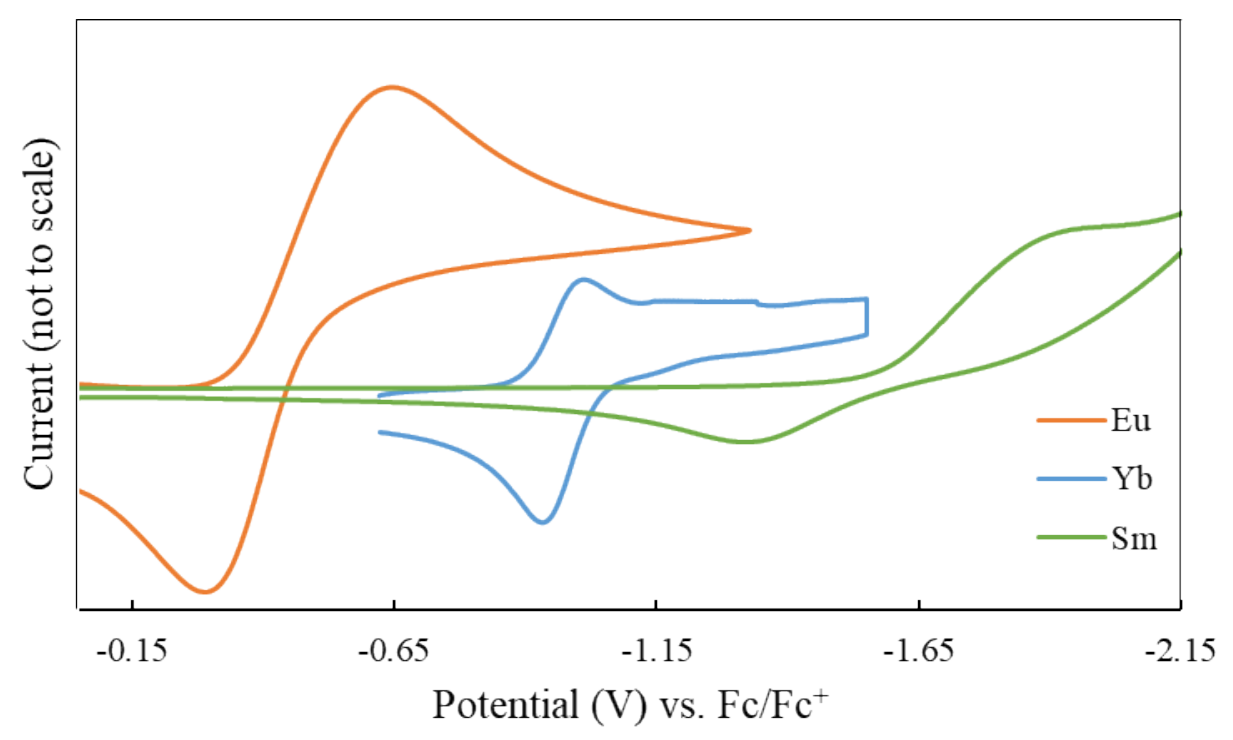

Figure S24. Three CV experiments for the Ln cryptates where the Yb couple is enhanced for better viewing $\left(T=25^{\circ} \mathrm{C}\right.$ and $\left.v=100 \mathrm{mV} / \mathrm{sec}\right)$. 
Table S1. Electrochemical data for four different scan types with [Cf(2.2.2-cryptand)](otf) 3 .

\begin{tabular}{|c|c|c|c|c|c|c|c|c|}
\hline Method & $\begin{array}{c}\text { Scan } \\
\text { Rate } \\
(\mathrm{mV} / \mathrm{sec})\end{array}$ & $\begin{array}{c}\mathrm{E}_{1 / 2} \\
(\mathrm{~V})\end{array}$ & $\begin{array}{c}\mathrm{E}_{\text {cathode }} \\
(\mathrm{V})\end{array}$ & $\begin{array}{c}\mathrm{E}_{\text {anode }} \\
(\mathrm{V})\end{array}$ & $\begin{array}{c}\text { Reversibility } \\
(\mathrm{mV})\end{array}$ & $\begin{array}{c}\mathrm{I}_{\mathrm{pc}} \\
(\mu \mathrm{A})\end{array}$ & $\begin{array}{c}\mathrm{I}_{\mathrm{pa}} \\
(\mu \mathrm{A})\end{array}$ & $\mathrm{I}_{\mathrm{pc}} / \mathrm{I}_{\mathrm{pa}}$ \\
\hline \multirow{5}{*}{ Long } & 10 & -1.56 & -1.66 & -1.46 & 200 & 5.73 & 3.80 & 1.51 \\
\cline { 2 - 9 } & 25 & -1.56 & -1.69 & -1.42 & 270 & 7.69 & 4.83 & 1.59 \\
\cline { 2 - 9 } & 50 & -1.53 & -1.75 & -1.3 & 448 & 7.31 & 8.26 & -- \\
\cline { 2 - 9 } & 100 & -1.55 & -1.83 & -1.26 & 566 & 18.9 & 8.93 & 2.12 \\
\cline { 2 - 9 } Short & 250 & -1.52 & -1.90 & -1.13 & 770 & 22.4 & 19.6 & -- \\
\cline { 2 - 9 } & 10 & -1.61 & -1.71 & -1.50 & 210 & 5.86 & 2.22 & 2.64 \\
\cline { 2 - 9 } & 25 & -1.60 & -1.76 & -1.43 & 330 & 12.6 & 2.91 & 2.77 \\
\cline { 2 - 9 } & 50 & -1.56 & -1.80 & -1.31 & 490 & 17.0 & 7.18 & 2.37 \\
\cline { 2 - 9 } & 100 & -1.54 & -1.84 & -1.23 & 610 & 27.8 & 12.6 & 2.21 \\
\hline \multirow{5}{*}{ Anodic } & 250 & -1.54 & -1.93 & -1.15 & 780 & 45.1 & 14.1 & -- \\
\cline { 2 - 9 } & 10 & -1.56 & -1.67 & -1.44 & 230 & 4.05 & 2.80 & 1.45 \\
\cline { 2 - 9 } & 25 & -1.55 & -1.71 & -1.40 & 310 & 5.67 & 4.56 & 1.24 \\
\cline { 2 - 9 } & 100 & -1.54 & -1.74 & -1.33 & 410 & 10.0 & 7.10 & 1.41 \\
\cline { 2 - 9 } & 250 & -1.49 & -1.78 & -1.22 & 560 & 13.4 & 11.3 & 1.19 \\
\cline { 2 - 9 } & 10 & -1.54 & -1.61 & -1.10 & 780 & 17.4 & -- & -- \\
\cline { 2 - 9 } & 25 & -1.53 & -1.62 & -1.44 & 180 & 7.88 & 5.24 & 1.50 \\
\cline { 2 - 8 } & 50 & -1.55 & -1.67 & -1.43 & 240 & 8.75 & 7.09 & 1.23 \\
\hline
\end{tabular}

Table S2. Adjusted concentrations of [Cf(2.2.2-cryptand)](otf) 3 with respect to the time

stamps and calculated evaporation rate.

\begin{tabular}{|c|c|c|c|}
\hline Time & Minutes Elapsed & THF Volume $(\mu \mathrm{L})$ & {$\left[\mathrm{Cf}(\mathrm{otf})_{3}\right](\mathrm{M})$} \\
\hline & 0 & 600 & \\
\hline 10:32 AM & 0 & 600.00 & $4.45 \mathrm{E}-03$ \\
\hline 10:33 AM & 1 & 596.18 & $4.48 \mathrm{E}-03$ \\
\hline $10: 34 \mathrm{AM}$ & 2 & 592.35 & $4.51 \mathrm{E}-03$ \\
\hline $10: 35 \mathrm{AM}$ & 3 & 588.53 & $4.54 \mathrm{E}-03$ \\
\hline $10: 37 \mathrm{AM}$ & 5 & 580.88 & $4.60 \mathrm{E}-03$ \\
\hline $10: 39 \mathrm{AM}$ & 7 & 573.23 & $4.66 \mathrm{E}-03$ \\
\hline $10: 44 \mathrm{AM}$ & 12 & 554.12 & $4.82 \mathrm{E}-03$ \\
\hline
\end{tabular}




\begin{tabular}{|c|c|c|c|}
\hline 10:45 AM & 13 & 550.29 & $4.86 \mathrm{E}-03$ \\
\hline 10:46 AM & 14 & 546.47 & $4.89 \mathrm{E}-03$ \\
\hline $10: 47 \mathrm{AM}$ & 15 & 542.65 & 4.92E-03 \\
\hline 10:49 AM & 17 & 535.00 & 4.99E-03 \\
\hline 10:53 AM & 21 & 519.70 & $5.14 \mathrm{E}-03$ \\
\hline 10:57 AM & 25 & 504.41 & $5.30 \mathrm{E}-03$ \\
\hline 11:01 AM & 29 & 489.11 & $5.46 \mathrm{E}-03$ \\
\hline 11:04 AM & 32 & 477.64 & $5.59 \mathrm{E}-03$ \\
\hline 11:09 AM & 37 & 458.52 & $5.83 \mathrm{E}-03$ \\
\hline $11: 12$ AM & 40 & 447.05 & $5.98 \mathrm{E}-03$ \\
\hline 11:14 AM & 42 & 439.41 & $6.08 \mathrm{E}-03$ \\
\hline 11:32 AM & 60 & 370.58 & $7.21 \mathrm{E}-03$ \\
\hline 11:34 AM & 62 & 362.93 & $7.36 \mathrm{E}-03$ \\
\hline 11:36 AM & 64 & 355.29 & $7.52 \mathrm{E}-03$ \\
\hline \multicolumn{4}{|c|}{ Intermission } \\
\hline 3:12 PM & 0 & 600.00 & $4.45 \mathrm{E}-03$ \\
\hline 3:13 PM & 1 & 596.18 & $4.48 \mathrm{E}-03$ \\
\hline 3:15 PM & 3 & 588.53 & $4.54 \mathrm{E}-03$ \\
\hline $3: 16 \mathrm{PM}$ & 4 & 584.71 & $4.57 \mathrm{E}-03$ \\
\hline 3:19 PM & 7 & 573.23 & $4.66 \mathrm{E}-03$ \\
\hline 3:22 PM & 10 & 561.76 & $4.76 \mathrm{E}-03$ \\
\hline $3: 24 \mathrm{PM}$ & 12 & 554.12 & $4.82 \mathrm{E}-03$ \\
\hline 3:28 PM & 16 & 538.82 & 4.96E-03 \\
\hline 3:38 PM & 26 & 500.58 & $5.34 \mathrm{E}-03$ \\
\hline 3:42 PM & 30 & 485.29 & $5.51 \mathrm{E}-03$ \\
\hline 3:44 PM & 32 & 477.64 & $5.59 \mathrm{E}-03$ \\
\hline 3:47 PM & 35 & 466.17 & $5.73 \mathrm{E}-03$ \\
\hline 3:50 PM & 38 & 454.70 & $5.88 \mathrm{E}-03$ \\
\hline 3:51 PM & 39 & 450.88 & $5.93 \mathrm{E}-03$ \\
\hline 3:53 PM & 41 & 443.23 & $6.03 \mathrm{E}-03$ \\
\hline 3:54 PM & 42 & 439.41 & $6.08 \mathrm{E}-03$ \\
\hline 3:56 PM & 44 & 431.76 & $6.19 \mathrm{E}-03$ \\
\hline 3:58 PM & 46 & 424.11 & 6.30E-03 \\
\hline 4:00 PM & 48 & 416.46 & $6.42 \mathrm{E}-03$ \\
\hline 4:04 PM & 52 & 401.17 & 6.66E-03 \\
\hline 4:08 PM & 56 & 385.87 & 6.92E-03 \\
\hline 4:10 PM & 58 & 378.23 & 7.06E-03 \\
\hline 4:15 PM & 63 & 359.11 & 7.44E-03 \\
\hline 4:20 PM & 68 & 339.99 & 7.86E-03 \\
\hline 4:23 PM & 71 & 328.52 & 8.13E-03 \\
\hline
\end{tabular}


Table S3. Electrochemical data for several $[\mathrm{Ln}(2.2 .2$-cryptand $)(\mathrm{THF})]\left[\mathrm{BPh}_{4}\right]_{2}(\mathrm{Ln}=\mathrm{Sm}$,

Eu) and Yb complexes.

\begin{tabular}{|c|c|c|c|c|c|c|c|}
\hline Complex & 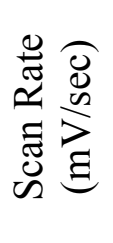 & $\begin{array}{l}\overrightarrow{\overrightarrow{0}} \\
\frac{D}{2} \\
\dot{0}\end{array}$ & $\begin{array}{l}\frac{0}{2} \\
\frac{0}{0} \\
\frac{0}{0} \\
\frac{0}{1} \\
\text { II }\end{array}$ & 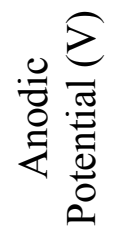 & 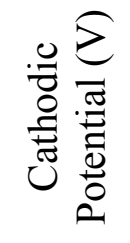 & 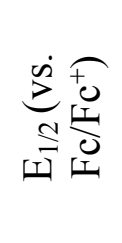 & 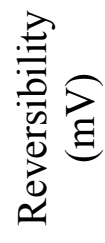 \\
\hline $\mathrm{Eu}$ & 100 & THF & $\mathrm{NPr}_{4} \mathrm{BAr}_{4}{ }_{4}$ & 0.068 & -0.035 & 0.017 & 103 \\
\hline $\mathrm{Yb}$ & 100 & THF & $\mathrm{NPr}_{4} \mathrm{BAr}_{4}{ }_{4}$ & -1.05 & -1.11 & -1.08 & 59.5 \\
\hline $\mathrm{Sm}$ & 500 & THF & $\mathrm{NPr}_{4} \mathrm{BAr}_{4}{ }_{4}$ & -1.57 & -1.84 & -1.71 & 271 \\
\hline
\end{tabular}




\section{Absorption and Emission Spectroscopy}

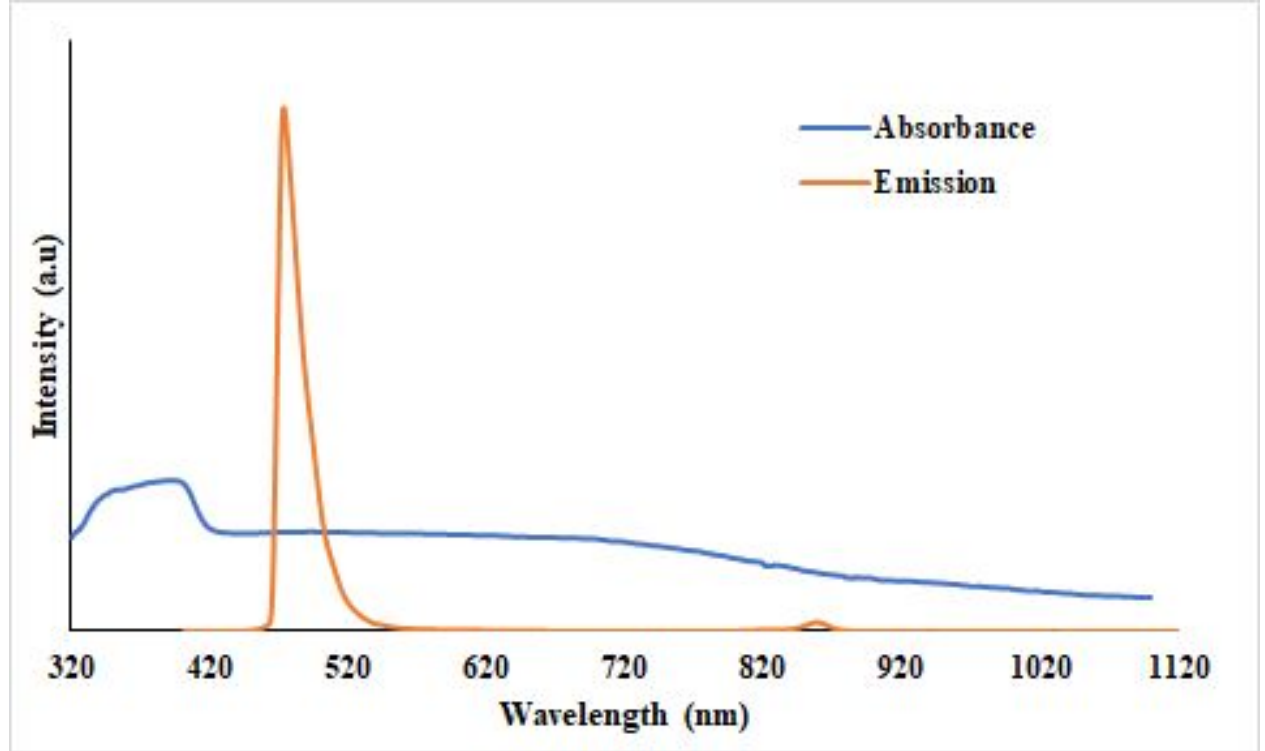

Figure S25. Luminescence from divalent $[\mathrm{Eu}(2.2 .2-\mathrm{cryptand})(\mathrm{THF})]\left[\mathrm{BPh}_{4}\right]_{2}$ shows a strong emission near $500 \mathrm{~nm}$. 
$[\operatorname{Sm}(2.2 .2)(T H F)][B P h 4]_{2}$
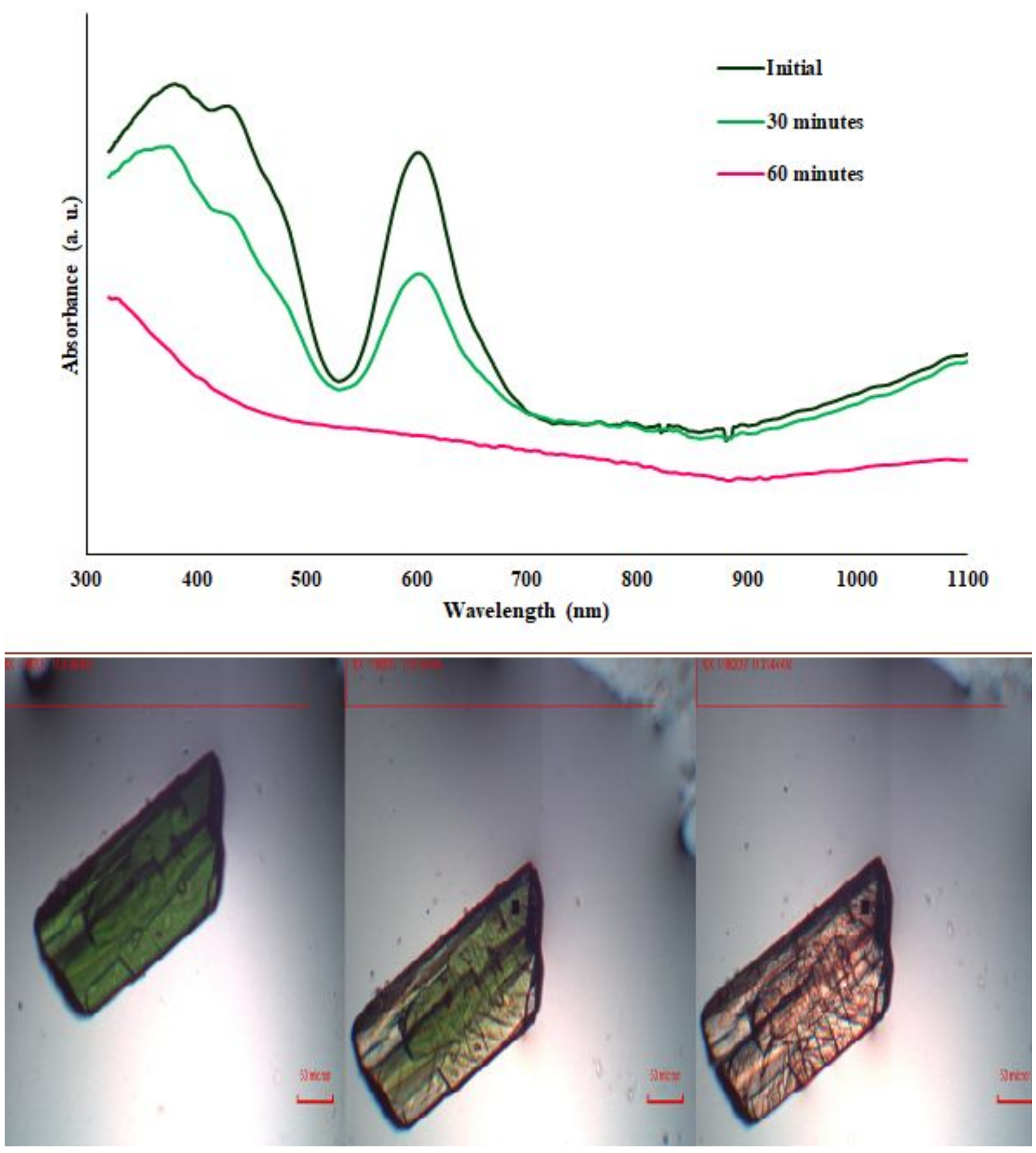
Figure S26. Absorption spectra of $\left[\mathrm{Sm}(2.2 .2 \text {-cryptand)(THF)][BPh }]_{2}\right.$ shows the characteristic broad features of divalent Sm near $400 \mathrm{~nm}$. Over time, the green crystals oxidize and lose these features.

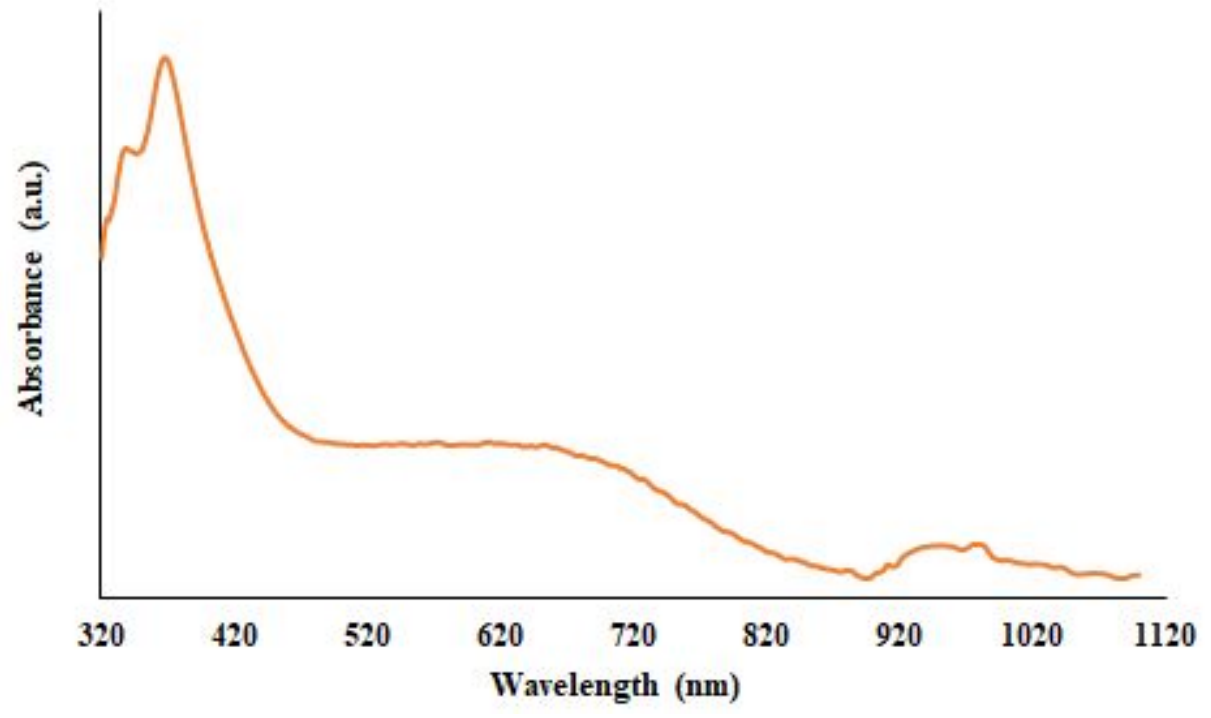

Figure S27. Absorption spectra for $\mathrm{Yb}\left(\mathrm{BPh}_{4}\right)_{2}$. 